\title{
Graphite Particle Reduction Process using High Energy Milling
}

\author{
Diah Hari Kusumawati ${ }^{1}$ \\ Department of Physics \\ Universitas Negeri Surabaya \\ Surabaya, Indonesia \\ 1diahkusumawati@unesa.ac.id
}

\author{
Muhammad Nurhuda, D.J. Djoko Herry Santjojo, \\ Masruroh \\ Department of Physics \\ Universitas Brawijaya \\ Malang, Indonesia
}

\begin{abstract}
Graphite is a material that has excellent mechanical and thermal properties, as well as a wide application level, especially in the form of nanoparticles. High Energy Milling $(H E M)$ is one of the methods used in the formation of nanoparticles by reducing particle size mechanically. In this research, variation of ball mill ratio to number of graphite in milling (2:1,3:1 and $4: 1)$ and milling time (1, 2, 3 and 4 hours), with rotation speed $750 \mathrm{rpm}$, to obtain graphite nanoparticles the optimum. Ball mill comparison to the amount of graphite in the process of milling, done by controlling the amount of graphite as much as 5.28 grams. The graphite nanoparticles formed through the HEM process have particle sizes ranging from 403 to $58 \mathrm{~nm}$. Graphite particle size with increasing time and ratio ball mill: graphite, smaller, except on variation of ratio ball mill : graphite, $2: 1$, with 4 hour milling time, this is supported by SEM data showing the change of graphite particles shape into flakes, so the particle diameter measurable increase.
\end{abstract}

\section{Keywords: graphite, high energy milling, particle size}

\section{INTRODUCTION}

Nanomaterial synthesis can be done through a top-down and bottom-up approach in reducing particle size. Top-down approach, namely the process of forming nano materials starting from bulk materials. The second approach is bottomup, namely the process of forming nano materials from the smallest scale. The methods grouped in a top-down approach include: attrition (milling), colloidal dispersion and thin layer formation using laser ablation and sputtering methods. The bottom-up method is lithography, polymerization and crystal growth from the gas or liquid phase. The reduction process can be done physically, a combination of physics and climax, thermal processes and electrical processes. High energy ballmilling is a mechanical powder milling process to reduce size, the formation of solid-state alloys, mixing two or more material components and changing the shape of particles using a high-energy ball mill. The product produced can be nano crystalline, amorphous and brush-crystalline. Mechanical formation of nanostructures can be done through mechanical milling with or without solvents, as well as a combination of mechanochemical milling. The milling process occurs in stirring and shaking, which involves collisions on the material using the principle of physical force. Powder breakdown occurs at macroscopic and microscopic levels, where the process goes through three stages, namely: 1). deformation 2). annihilation and recombination 3) grain orientation. The nanomaterial formation process has different weaknesses and advantages. In top-down techniques, nanostructure surface imperfections often occur, defects, contaminants and internal stresses occur. This will affect the physical properties and chemical properties of the nanostructures, including causing inelastic surface scattering which will reduce conductivity. The bottom-up technique produces nano materials with small defects, homogeneous chemical composition and better order.

Based on the research of Shukla et al, 2013[1], where milling was carried out on $\mathrm{Cu} / \mathrm{CNT}$ (copper-carbon nanotube composite) composites, by varying $0.2 ; 5$ and 10 volume $\%$ CNT in $\mathrm{Cu}$ and milling time up to 20 hours at 5 hours intervals, it was found that the milling process produced composites with smaller particle size on SWCNT $\mathrm{Cu}-10$ volume \% composite composites. In other compositions 0.2 and 5 volume $\%$ particle size increases, this is because in the mechanical alloy process there is a cold-welding phenomenon which results in agglomeration so that it increases particle size from the initial size. Other research [2] concerning the effect of milling process on multiwall carbon nanotubes morphology (MWCNT) with variations in milling speed, milling time, ball mill number, BPR (ball-to-powder ratio) and milling environment. Morphological changes in MWCNT due to milling have several forms, including the ends of rounded tubes, open (broken) tube ends, defects, and amorphous tubes. The results of the study by Osinska M, 2015 [3], about the modification of carbon-metal composites using high-energy ball milling with a focus on the effects of HEM on the electrochemical activity of the composite from some of these studies, it is necessary to do basic research on carbon before carbon is used or composted with other materials. So that the basic ingredients in the form of nanoparticles are expected to make it easier in the application and composting process. In addition, with carbon whose particles are nano-sized, the application level of the carbon will be wider. Milling will result in changes in material microstructure, where particle size is an important structural parameter of the nanomaterial [4]. High energy when the milling process determines the 
occurrence of a chemical reaction because it increases the diffusion rate of the material being milled.

\section{MATERIALS AND METHODS}

\section{A. Materials}

The basic material used is graphite flakes with $99 \%$ purity carbon base, 325 mesh particle size.

\section{B. Methods}

The basic material is graphite with $99 \%$ purity, milled with high energy milling for 1, 2, 3 and 4 hours with a ball-mill ratio: graphite of $2: 1 ; 3: 1$; and $4: 1$. The milling process is carried out in each time variation and graphite mass ratio to the ball-milling period. High energy milling on graphite is done by controlling the rotational speed of the milling process at 750 rpm, with an hour time interval. Graphite resulting from milling will be characterized by PSA (Particle Size Analyzer) to determine particle size, with variations in milling time and graphite mass ratio to the ball-milling period. The microstructure of graphite before and after the milling process was characterized using SEM (Scanning Electron Microscope).

\section{RESULTS AND DISCUSSION}

Graphite which has been milled with time variation and variation of graphite mass ratio to the ball-mill period, is characterized by PSA to determine particle size after milling process using the High Energy Milling method. Graphite with a milling time of 1 hour on a variation of ball-mill mass ratio: graphite mass, the smaller the particle size obtained in the greater PBR ratio variation, but the exception is the PBR ratio of 4: 1 the particle size of graphite is greater. This condition is caused by the large ball-mill mass, which will cause a large force on the graphite to be milled, so that the force applied to graphite causes the graphite particles to deform due to collisions between the graphite particles and the ball-mill which results in the bulk graphite particles being transformed into shapes plate. Graphite particle measurement results at 1 hour milling time are given in table 1 .

TABLE I. GRAPHITE PSA RESULTS ON PBR VARIATION WITH 1 HOUR MILLING TIME

\begin{tabular}{|c|c|c|c|c|c|}
\hline $\begin{array}{c}\text { Sample } \\
\text { Code }\end{array}$ & $\begin{array}{c}\text { Ball Mill } \\
\text { Alumina } \\
\text { (gram) }\end{array}$ & $\begin{array}{c}\text { Graphite } \\
\text { (gram) }\end{array}$ & $\begin{array}{c}\text { Time } \\
\text { Milling } \\
\text { (hour/s) }\end{array}$ & $\begin{array}{c}\text { Peak 1 } \\
\text { (nm) }\end{array}$ & $\begin{array}{c}\text { Peak 2 } \\
\text { (nm) }\end{array}$ \\
\hline A & 10.56 & 5.28 & 1 & 343.1 & - \\
\hline B & 15.84 & 5.28 & 1 & 119.9 & 20.12 \\
\hline C & 21.12 & 5.28 & 1 & 403.1 & 97.24 \\
\hline
\end{tabular}

The particle size of graphite has decreased in PBR 2:1 and 3:1, but in PBR 4:1 there are particles of increasing size. Particle size changes are caused by collisions between graphite particles and the ball mill used and friction force [1]. The milling process is described as a kinetic process where there is a transfer of kinetic energy to collisions between the ball mill and graphite. Ball mill is assumed to move free fall at a speed equal to the speed of gravity of the earth at a certain time interval.

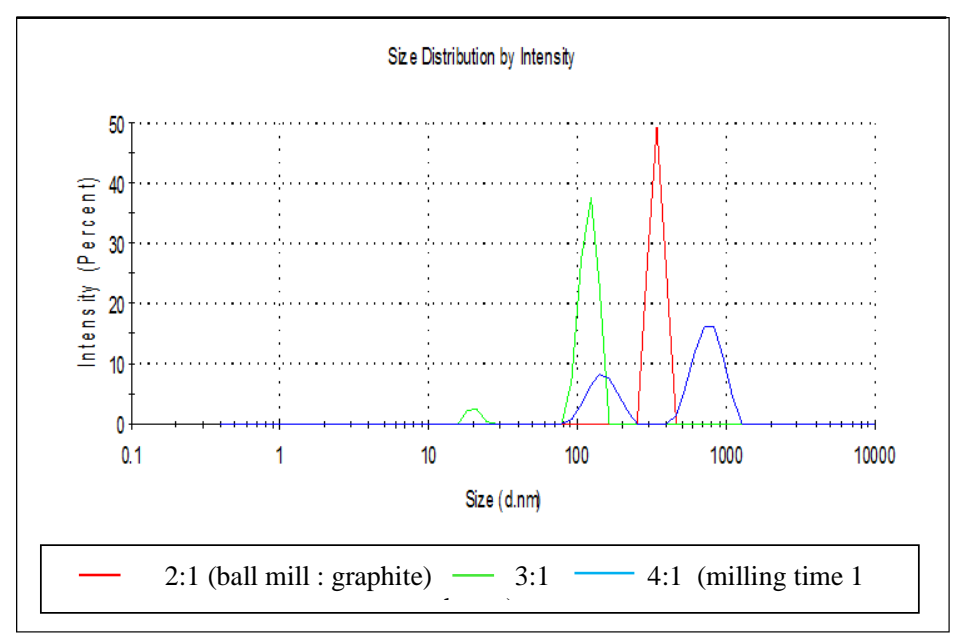

Fig. 1. Particle size of graphite in PBR variation, milling time 1 hour

PBR has a significant effect in reducing the particle size of graphite, with a large ball mill mass can reduce the particle size more optimally, at longer milling times. The PSA results for all variations are listed in the table below.

TABLE II. PSA RESULTS ALL VARIATION HIGH-ENERGY MILLING

\begin{tabular}{|c|c|c|c|c|c|}
\hline $\begin{array}{c}\text { Sample } \\
\text { Code }\end{array}$ & $\begin{array}{c}\text { Ball Mill } \\
\text { Alumina } \\
\text { (gram) }\end{array}$ & $\begin{array}{c}\text { Graphite } \\
\text { (gram) }\end{array}$ & $\begin{array}{c}\text { Milling } \\
\text { Time } \\
\text { (hour/s) }\end{array}$ & $\begin{array}{c}\text { Peak 1 } \\
\text { (nm) }\end{array}$ & $\begin{array}{c}\text { Peak 2 } \\
\text { (nm) }\end{array}$ \\
\hline A & 10.56 & 5.28 & 1 & 343.1 & - \\
\hline D & 10.56 & 5.28 & 2 & 903.4 & 109,2 \\
\hline G & 10.56 & 5.28 & 3 & 302.8 & 83.66 \\
\hline J & 10.56 & 5.28 & 4 & 244.8 & - \\
\hline B & 15.84 & 5.28 & 1 & 119.9 & 20.12 \\
\hline E & 15.84 & 5.28 & 2 & 653.9 & - \\
\hline H & 15.84 & 5.28 & 3 & 243.9 & - \\
\hline K & 15.84 & 5.28 & 4 & 159.4 & - \\
\hline C & 21.12 & 5.28 & 1 & 403.1 & 97.24 \\
\hline F & 21.12 & 5.28 & 2 & 237.6 & 21.04 \\
\hline I & 21.12 & 5.28 & 3 & 91.28 & - \\
\hline L & 21.12 & 5.28 & 4 & 58.77 & - \\
\hline
\end{tabular}

Based on Table 2, it can be seen that the reduced particles are smaller in size at 4:1 PBR (21.12: 5.28), where the particle size gets smaller at longer milling times. Whereas for smaller PBR (smaller ball mill times), particle reduction is not proportional to milling time. At 2 hours milling time for PBR $2: 1$ and $3: 1$, the milling process does not reduce graphite particles, but the particle size is larger than the graphite particle size before the milling process. This is because the collision 
and friction processes between ball mill and graphite only cause the graphite particles to be deformed but not reduced in particle size. In all variations of PBR, a change in particle size smaller than the PBR 2: 1 and 3: 1 at the milling time 2 hours. However, when the milling time is added, the particle size is smaller, as shown in Figure 2. Increasing particle size at 2 hours milling time (in PBR 2: 1 and 3: 1), due to the milling process does not break graphite particles, but only causes deformation of graphite particles so that particles accumulate and form aggregates larger than the initial particle size. The milling process in the form of collisions and friction causes particle buildup. For 4: 1 PBR, the longer the milling time, the smaller the particle size, but the reduction process is no longer significant at 3 hours to 4 hours of milling, where the particle size is almost the same at 3 hours to 4 hours. The effect of PBR variation and milling time on particle size can be seen in Figure 2 and 3.

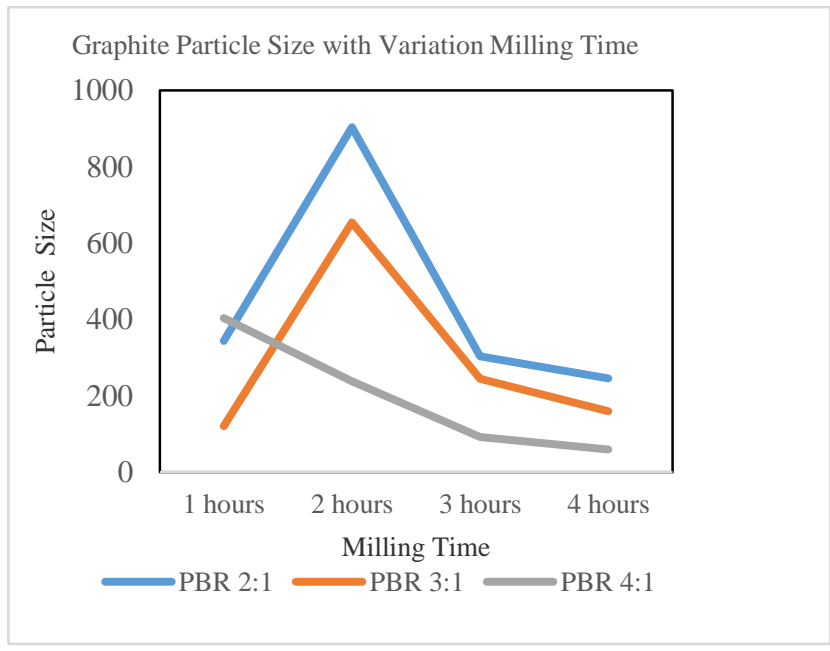

Fig. 2. Graph of the effect variation milling time on particle size

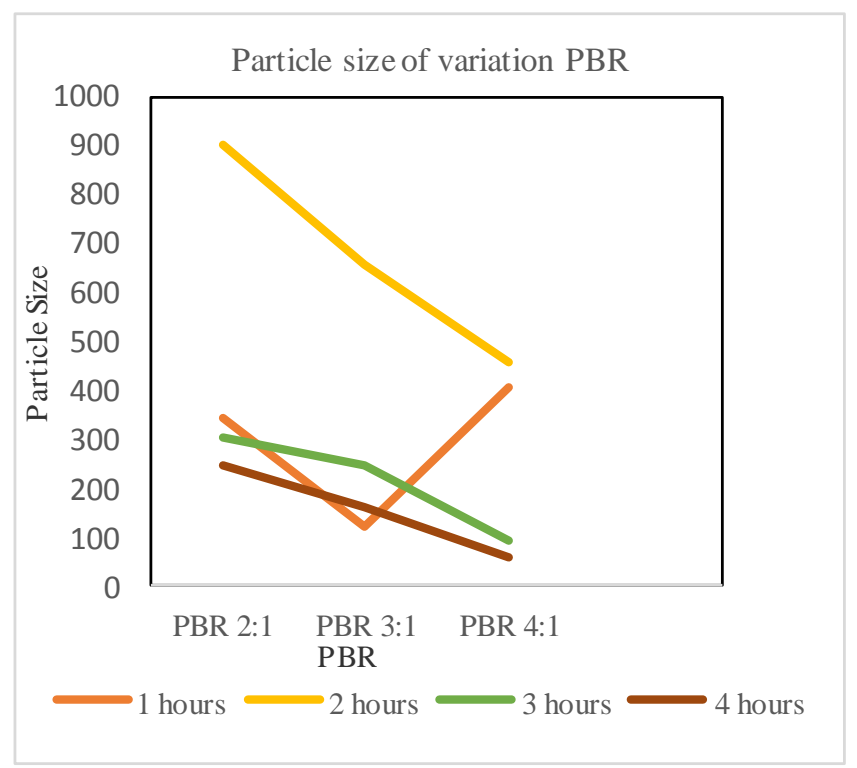

Fig. 3. Graph of the effect variation PBR on particle size
The results of particle reduction in the most optimum PBR variation were found in 4:1 PBR and 4 hours milling time, where the particle size became smaller and reached $58 \mathrm{~nm}$. On the variation of 2 hours milling time there is graphite which has a larger particle size after the milling process, this is because the reduction is not perfect and the particles are only deformed to change into flat or plate shapes. PSA results are also supported by SEM results, which are shown in the Figure 4.

Graphite before the milling process (Figure 4 a.), the particle size is more evenly distributed but still on a micro scale. After a 2-hour milling process, the particle size gets bigger because the collision process on the particles only causes deformation of the particles, not to the particle reduction process (Figure 4.b). SEM results show that the graphite particles are flat-shaped, and an agglomeration process occurs. Particles appear to agglomerate and accumulate with other particles.

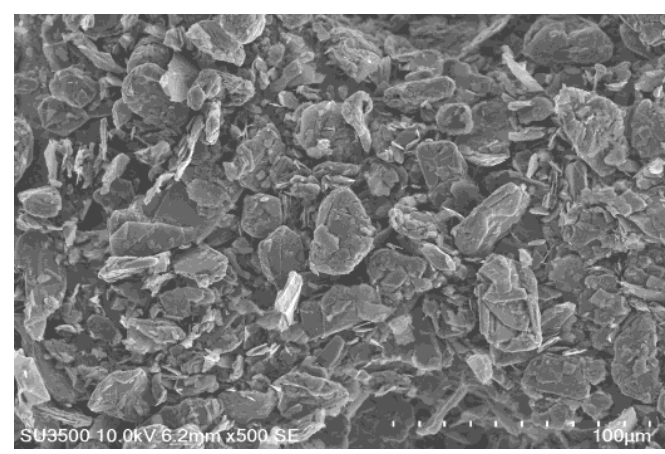

(a) Graphite



(b) HEM PBR 4:1, 2 hours

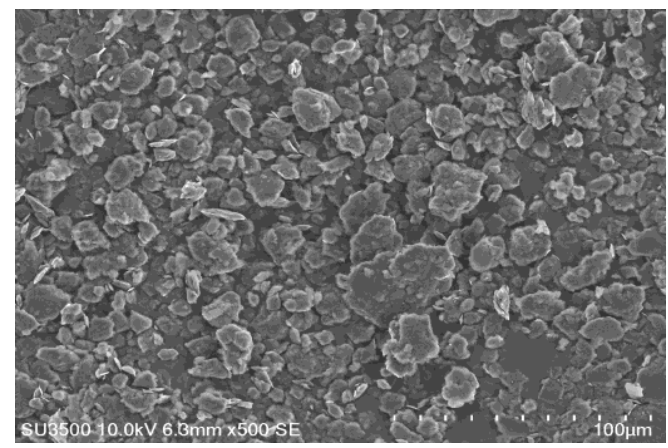

(c) HEM PBR 4:1, 4 hours

Fig. 4. SEM of graphite without milling and graphite milling 2 and 4 hours 
The agglomeration that appears on the results of milling will result in decreased mechanical properties of graphite and graphite composites [5]. Milling process with a longer time, will make particle reduction more optimum and homogeneity of graphite higher [1] [6], this is supported by the results of SEM in Figure $4 \mathrm{c}$, where the size of graphite particles is more homogeneous and agglomeration has been reduced.

The mechanical properties of graphite will increase when the graphite particles are well reduced and the homogeneity of the graphite is high. However, graphite will have higher mechanical properties when it is composited with other materials, such as aluminum, iron or organic materials [3][7].

EDX results show the presence of impurity elements after the milling process in the form of element O. Additional elements that appear due to the milling process are not in a vacuum and during milling there is friction with the ball mill which results in the material from the ball mill being reduced to graphite [7].

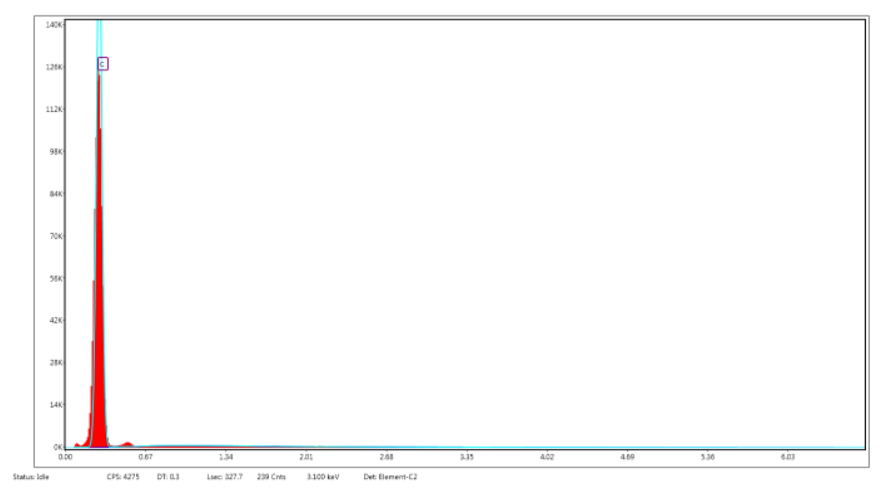

Fig. 5. EDX results of graphite

Graphite reduction results using high-energy milling are also affected by the rotational speed of the milling process. In this study the milling speed was controlled by $750 \mathrm{rpm}$.

\section{CONCLUSION}

The milling process can reduce graphite particle size with optimum results with a variation of 4: 1 PBR and 4 hours milling time. The reduced graphite particle size ranges from 58 $\mathrm{nm}$ (according to PSA results), with good homogeneity seen from the results of SEM and EDX. Milling can be processed in a longer time, but it is necessary to pay attention to the tube where the milling and ball mill are used.

\section{REFERENCES}

[1] A.K. Shukla, N. Nayan, S.V.S.N. Murty, K. Mondal, S.C. Sharma, K.M. George, and S.R. Bakshi, "Processing copper-carbon nanotube composite powders by high energy-milling", Mater. Charact., 84, 2013, pp. 58-66.

[2] W.M. Tucho, H. Mauroy, J.C. Wamsley, S. Deledda, R. Holmestad and B.C. Hauback, "The effects of ball milling on morphology of multiwall carbon nanotubes", Scr. Mater., 63, 2010, pp. 637-640.

[3] M. Osinska, "Modification of carbon-metal composites using highenergy ball milling", Microp. Mesop. Mater., 214, 2015, pp. 95-100.

[4] F.D. Ariffin, R. Hasham, M. Abdulhamid, A.M. Eid, A.T. Mohamed, E.I. Keleb, A. Elmahgoubi, Y.S. Issa, and N.A. Elmarzugi, "Effect of techniques in preparing VCO nanoparticles", IOSR-JBB, vol. 1, 2015, pp. 121-124.

[5] M.N. Kumar, M. Mahmoodi, M. TabkhPaz, S.S. Park, X. Jin, "Characterization and micro end milling of graphene nano platelet and carbon nanotube filled nanocomposites“, J. Mater. Process. Tech., 249, 2017, pp. 96-107.

[6] H. Xia, J. Wang, B. Huang, Z. Shi, G. Liu, and G. Qiao, "The influence of ball-milling on improving the performance of mesocarbon microbeads based carbon blocks", Mater. Scie. Eng. A, 529, 2011, pp. 282-288.

[7] M.R. Basariya, V.C. Srivastava, and N.K. Mukhopadhyay, "Microstructural characteristics and mechanical properties of carbon nano tube reinforced aluminum alloy composites produced by ball milling", Mater. and Des., 64, 2014, pp. 542-549. 